\title{
RELATIONSHIPS BETWEEN MICROSTRUCTURAL INSTABILITIES AND MECHANICAL BEHAVIOUR IN NEW GENERATION NICKEL-BASED SINGLE CRYSTAL SUPERALLOYS
}

\author{
O. Lavigne, C. Ramusat, S. Drawin, P. Caron, D. Boivin, J.-L. Pouchou \\ ONERA (Office National d'Etudes et de Recherches Aérospatiales), 29 Avenue de la Division Leclerc, F-92322 Châtillon, France
}

Keywords: Single crystal, Rhenium, Ruthenium, Secondary reaction zone, Cellular colony

\begin{abstract}
Microstructural instabilities occurring in two new generation single crystal nickel-based superalloys containing additions of both $\mathrm{Re}$ and $\mathrm{Ru}$ have been characterised by means of electron backscatter diffraction (EBSD). Cellular colonies develop in the MC632 experimental alloy at subgrain boundaries with misorientations higher than $10^{\circ}$. The role of these microstructural instabilities in the mechanical behaviour was investigated. After creep at high temperature microcracks are observed at the limit of the cellular colonies but these defects are not more frequent than those initiating from micropores or within the dendrites. As only a low volume fraction of $\gamma-\gamma^{\prime}$ alloy is involved in this transformation, the influence of this phenomenon on the alloy creep strength is negligible. Secondary reaction zones (SRZ) were observed beneath Pt-modified aluminide coating in the MC544 superalloy. EBSD analysis clearly demonstrated the polycrystalline structure of these SRZ. Despite the presence of internal grain boundaries, the SRZ are not preferential sites for premature failure initiation. However, the stress-rupture life is adversely affected by the reduction of the load-bearing section of safe $\gamma-\gamma$ alloy. The decrease of low cycle fatigue (LCF) strength observed at $650^{\circ} \mathrm{C}$ for coated MC544 compared to the bare alloy was mainly attributed to premature crack initiation within the aluminide coating and not from the SRZ. During LCF tests at $950^{\circ} \mathrm{C}$ of coated MC544, numerous cracks also initiate from the aluminide coating but then remain restricted to the SRZ area. The failure initiates at internal casting porosities. The slight LCF strength reduction observed in these conditions was attributed to the load bearing section reduction of unaffected $\gamma-\gamma^{\prime}$ alloy.
\end{abstract}

\section{Introduction}

High levels of alloying elements in $\boldsymbol{\gamma}-\boldsymbol{\gamma}^{\prime}$ nickel-based superalloys may leave them prone to different types of microstructural instabilities likely to have deleterious effects on their mechanical properties. This issue is particularly critical in the case of the most recent superalloys for single crystal turbine blade applications, in which the content of refractory elements such as Mo, W, Ta, Re and more recently $\mathrm{Ru}$ has been progressively increased to improve the high temperature capability of these materials [1]. The most known type of microstructural instability is the precipitation from the supersaturated $\gamma$ matrix of topologically close-packed (TCP) phases such as $\sigma, \mathrm{P}, \mu$ or Laves phases after long time exposure at temperatures above $900^{\circ} \mathrm{C}[2,3]$. The development of second and third generation single crystal superalloys with increasing amounts of Re was conducted by taking into account this specific issue. Indeed this alloying element which partitions preferentially to the $\gamma$ matrix strongly promotes the formation of Re-rich $\sigma$ or P phases. As an example, small amounts of TCP phases were reported to appear during high temperature exposures in third generation superalloys such as René N6 [4] and CMSX-10 [4, 5]. Such a phenomenon is likely to affect the mechanical behaviour in the following ways: i) solid solution softening due to the local depletion in strengthening alloying elements which participate in the formation of the TCP phases; ii) decrease of ductility and toughness due to initiation of microcracks at these brittle intermetallic particles; iii) decrease of the creep strength due to local disruption of the regular $\gamma-\gamma^{\prime}$ microstructure. It must however be pointed out that a small volume fraction of TCP phases can be sometimes tolerated in single crystal superalloys without deterioration of their mechanical properties [4-6].

On the other hand, TCP phase particles were also observed in association with cellular transformations occurring locally in some superalloys containing about 5 to $6 \mathrm{wt} . \% \operatorname{Re}[4,5,7-10]$. A distinction was drawn between cellular colonies developing from subgrain boundaries or within the dendrite cores and secondary reaction zones forming beneath protective coatings or thermal barrier bond coats such as nickel aluminides or MCrAlY coatings. However, both types of microstructural instabilities exhibit similar features: a $\gamma^{\prime}-\mathrm{Ni}_{3} \mathrm{Al}$-based matrix containing elongated particles of $\gamma$ phase and needle-like Re-rich TCP phase particles. As compared to TCP phase precipitation from the $\gamma$ matrix, these cellular transformations cause a heavier modification of the surrounding $\gamma$ $\gamma$ ' microstructure. However, only limited information concerning the possible harmfulness of these cellular transformations in relation with the mechanical behaviour of the superalloys has been published.

The purpose of the present work is therefore to analyse the microstructural instabilities likely to occur in new generation single crystal superalloys containing additions of both $\mathrm{Re}$ and $\mathrm{Ru}$ elements and to evaluate their impact on mechanical properties through detailed microstructural investigations.

\section{Materials}

The chemical compositions of the alloys of this study are reported in Table I. AM1 is a first generation single crystal superalloy which does not contain Re [1]. It is used as turbine blade material in the M88 Snecma engine and was selected here for the sake of comparison. MC544 is a new generation single crystal superalloy showing an optimal specific creep strength, developed for high temperature use [11]. It is under evaluation at an industrial scale at Snecma Moteurs and Turbomeca under the name of MC-NG [10]. MC632 is an experimental single crystal superalloy with reduced 
Table I. Chemistries (wt.\%) of the Single Crystal Superalloys

\begin{tabular}{|c|c|c|c|c|c|c|c|c|c|c|c|}
\hline Alloy & $\mathrm{Ni}$ & $\mathrm{Co}$ & $\mathrm{Cr}$ & $\mathrm{Mo}$ & $\mathrm{Re}$ & $\mathrm{Ru}$ & $\mathrm{W}$ & $\mathrm{Al}$ & $\mathrm{Ti}$ & $\mathrm{Ta}$ & Others \\
\hline AM1 & Bal. & 6.5 & 7.8 & 2 & - & - & 5.7 & 5.2 & 1.1 & 7.9 & - \\
\hline MC544 & Bal. & - & 4 & 1 & 4 & 4 & 5 & 6 & 0.5 & 5 & $0.1 \mathrm{Si} ; 0.1 \mathrm{Hf}$ \\
\hline MC632 & Bal. & - & 5 & 1.2 & 3.5 & 2 & 6 & 5.4 & 1.3 & 6 & $0.1 \mathrm{Si} ; 0.1 \mathrm{Hf}$ \\
\hline
\end{tabular}

levels of $\mathrm{Re}$ and $\mathrm{Ru}$ and higher concentrations of $\mathrm{Ti}$ and $\mathrm{Ta}$ as compared to MC544. The initial purpose when designing MC632 was to strengthen the $\gamma^{\prime}$ phase by increasing the $(\mathrm{Ti}+\mathrm{Ta}) / \mathrm{Al}$ ratio, while limiting the cost and the density by decreasing the contents of $\mathrm{Re}$ and $\mathrm{Ru}$. As will be seen below, the choice of MC632 was justified by its tendency to form cellular colonies which makes it well suited for the scope of this study.

Small-scale laboratory heats of AM1 and MC632 were melted in a high vacuum induction furnace at ONERA, while MC544 was melted by Aubert et Duval (Les Ancizes, France) in an industrial furnace. All single crystal rods were directionally cast at ONERA by the withdrawal process using $<001>$ oriented seeds, with a temperature gradient of about $40^{\circ} \mathrm{C} . \mathrm{cm}^{-1}$ and a withdrawal rate of $10 \mathrm{~cm} \cdot \mathrm{h}^{-1}$. The single crystal rods had orientations within $5^{\circ}$ off a $<001>$ direction. They were fully solution heat treated using the following procedures:

- AM1: $1300^{\circ} \mathrm{C} / 3 \mathrm{~h} /$ air cooling

- MC544: $1310^{\circ} \mathrm{C} / 3 \mathrm{~h}$, heating for 10 hours at a rate of $3^{\circ} \mathrm{C} \cdot \mathrm{h}^{-1}$, $1340^{\circ} \mathrm{C} / 3 \mathrm{~h} /$ air cooling.

- MC632: $1330^{\circ} \mathrm{C} / 6 \mathrm{~h}$, heating for 5 hours at a rate of $2^{\circ} \mathrm{C} \cdot \mathrm{h}^{-1}$, $1340^{\circ} \mathrm{C} / 7 \mathrm{~h} /$ air cooling.

All materials for uncoated specimen testing were then given a two-step ageing treatment for 4 hours at $1100^{\circ} \mathrm{C}$ followed by air cooling, then 24 hours at $850^{\circ} \mathrm{C}$, air cooling.

Some mechanical tests were performed on MC544 specimens coated at ONERA with a Pt-modified nickel aluminide. The specimens were machined by smooth grinding from solution heat treated rods. The coating was made by first electrodepositing a 7 $\mu \mathrm{m}$ thick layer of platinum on previously wet sand blasted surface. This was followed by a diffusion treatment at $850^{\circ} \mathrm{C}$ for 2 hours and a low-activity vapour phase aluminizing treatment at $1080^{\circ} \mathrm{C}$ for 6 hours. An ageing heat treatment for 24 hours at $850^{\circ} \mathrm{C}$ was finally applied.

\section{Experimental Procedures}

Electron Backscatter Diffraction (EBSD) analysis was performed on polished transverse sections of single crystal rods in a Zeiss DSM960 scanning electron microscope equipped with TSL (TexSEM Lab., USA) EBSD software. Micrographs and fractographs were acquired using a conventional Zeiss DSM962 scanning electron microscope (SEM). X-ray energy dispersive spectroscopy (EDS) in the SEM was used for chemical analysis of the various constitutive phases.

Constant load tensile creep-rupture tests were conducted in air on cylindrical specimens having a $3 \mathrm{~mm}$ gauge diameter and a 20 $\mathrm{mm}$ gauge length. Strain controlled, fully reversed low cycle fatigue (LCF) tests were run in argon at a frequency of $0.33 \mathrm{~Hz}$ on cylindrical specimens with a gauge diameter of $4.85 \mathrm{~mm}$.

\section{Experimental Results}

\section{Cellular Colonies at Subgrain Boundaries}

Microstructures. A comparative study of the formation of cellular colonies at subgrain boundaries was carried out on both AM1 and MC632. Crystal orientation maps have been obtained by EBSD analysis at a large scale on the whole section of AM1 and MC632 $12 \mathrm{~mm}$ diameter rods. Boundaries between subgrains have been drawn as a function of misorientation angle, i.e. the angle of rotation about the crystallographic axis common to two subgrains which brings the two crystal lattices into coincidence (Figure 1). For both superalloys the cumulative length of the low angle boundaries (misorientation angles within the $15^{\circ}, 10^{\circ}$ ] range) represents about $75 \%$ of the total subgrain boundary length. The remaining $25 \%$ correspond to high angle boundaries belonging to the $] 10^{\circ}, 15^{\circ}$ ] interval. In neither case, misorientation angles higher than $15^{\circ}$ were observed.

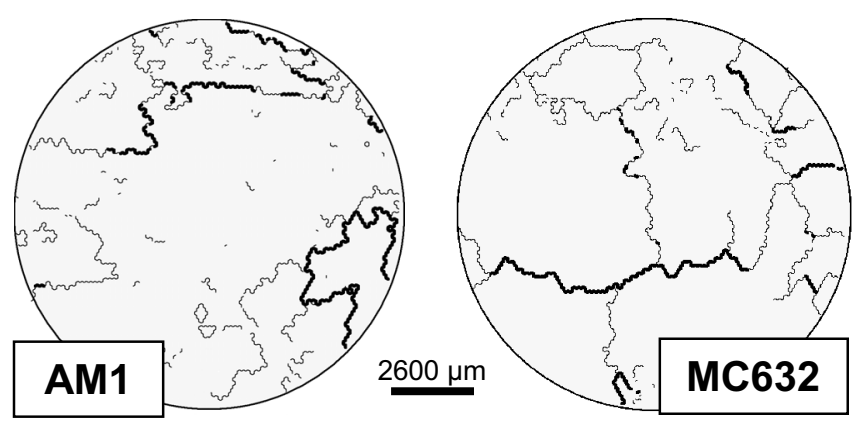

Figure 1. Subgrain boundaries as a function of the relative misorientation angle: light grey for $15^{\circ}, 10^{\circ}$ ] and black for $] 10^{\circ}$, $15^{\circ}$ ] boundaries.

The microstructure of all subgrain boundaries in the two superalloys has been observed in a systematic way by SEM. The evolution of a same boundary was followed from the initial heat treated state to further aged states at 950,1050 and $1100^{\circ} \mathrm{C}$ for 200 hours.

In the case of AM1 no significant modification of the subgrain boundary microstructure in relation to the ageing treatment was noticed regardless the misorientation (Figures $2 \mathrm{a}$ and $2 \mathrm{~b}$ ). Only the classical coarsening of the $\gamma-\gamma$ ' structure at high temperature occurs. A similar behaviour was observed in Re-rich MC632 alloy but only for the low angle boundaries (Figures $2 \mathrm{c}$ and $2 \mathrm{~d}$ ). On the other hand some cellular transformation can be found at high angle boundaries even immediately after the initial heat treatment (Figure 3a): the fine standard $\gamma-\gamma^{\prime}$ structure is transformed into a coarser one composed of a $\gamma^{\prime}$ matrix containing elongated particles of $\gamma$ phase and needle-like TCP phases. 

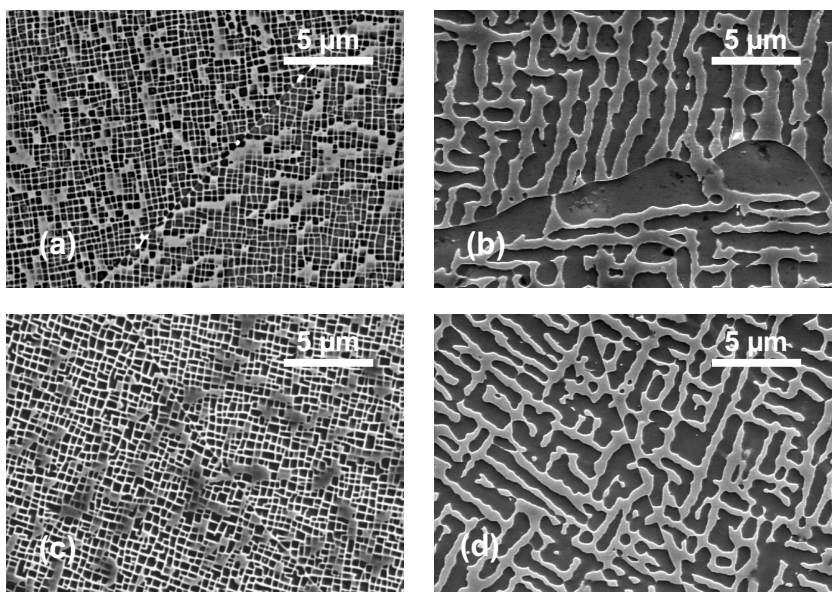

Figure 2. SEM micrographs (backscattered electron mode) of low angle subgrain boundaries; (a) as heat treated AM1; (b) AM1 aged at $1100^{\circ} \mathrm{C} / 200$ hours; (c) as heat treated MC632; (d) MC632 aged at $1100^{\circ} \mathrm{C} / 200$ hours.

EDS semi-quantitative analysis showed that these last precipitates are composed mainly of $\mathrm{Re}, \mathrm{Mo}, \mathrm{Ni}$ and $\mathrm{Cr}$ and to a lesser extent of $\mathrm{Ru}$ and $\mathrm{W}$. About $10 \%$ of the $] 10^{\circ}, 15^{\circ}$ ] boundary length presents such cellular colonies extending up to $5 \mu \mathrm{m}$ maximum on one side of the subgrain boundary.

After high temperature exposure cellular colonies have been observed on the whole length of the high angle boundaries in MC632 (Figures $3 \mathrm{~b}$ to $3 \mathrm{~d}$ ). They extend from $5 \mu \mathrm{m}$ on one side of the boundary at $950^{\circ} \mathrm{C}$ to more than $10 \mu \mathrm{m}$ on both sides of the boundary after $1100^{\circ} \mathrm{C}$ ageing. As a consequence, 1 to $2 \%$ of the superalloy sample section is affected by such microstructural defects at these temperatures. In addition, TCP phase precipitates have also been observed in the dendrite cores after ageing above $1050^{\circ} \mathrm{C}$. However, they were never associated with cellular transformation. This observation confirms the influence of the misorientation parameter on the development of cellular colonies.
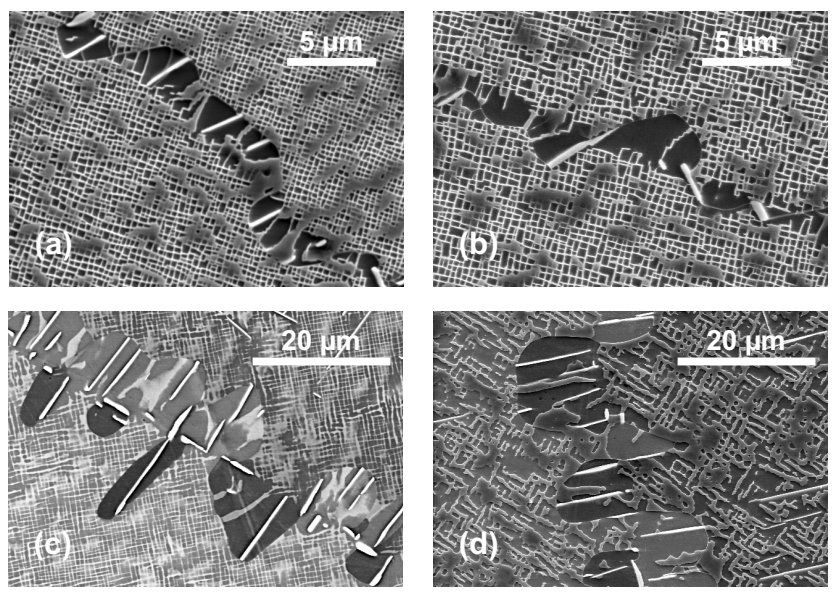

Figure 3. SEM micrographs (backscattered electron mode) of high angle subgrain boundaries in MC632: (a) as heat treated; aged for 200 hours at $950^{\circ} \mathrm{C}(\mathrm{b}), 1050{ }^{\circ} \mathrm{C}(\mathrm{c})$ and $1100^{\circ} \mathrm{C}(\mathrm{d})$.
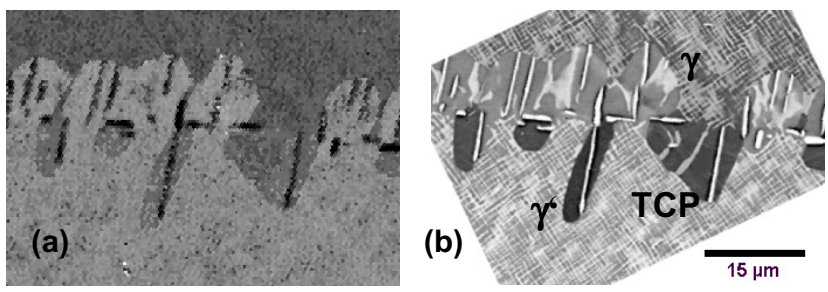

Figure 4. Cellular colony in MC632 aged at $1050^{\circ} \mathrm{C}$ for 200 hours: (a) EBSD orientation map (inverse pole figure ND); (b) SEM micrograph (backscattered electron mode).

These comparative observations show that the cellular colony formation is promoted by both a specific bulk chemistry of the alloy and a high misorientation between subgrains.

In order to further characterize the cellular colony microstructure in MC632 alloy, EBSD orientation maps have been obtained at a smaller scale. From an inverse pole figure showing the position of a sample direction (here sample normal ND) relative to the crystal reference frame, it appears that a cellular colony has the same crystallographic orientation as its parent subgrain (Figure 4). This shows that the formation of cellular colonies at a high angle boundary does not change the initial misorientation between the two corresponding subgrains. Only the boundary shape and length are modified. The subgrain boundaries affected by the nucleation of cellular colonies become serrated and as a consequence their length increases. On the other hand, when cellular colonies grow simultaneously on both sides of the subgrain boundary, an additional high angle subgrain boundary is created.

Creep Behaviour. Microstructural observations were performed on MC632 single crystal specimens failed after creep at high temperature in order to assess possible damage in the vicinity of cellular colonies.

Figures $5 \mathrm{a}$ and $5 \mathrm{~b}$ illustrate the different types of microstructural instabilities observed in MC632 after creep at $1050^{\circ} \mathrm{C}$. Cellular colonies were observed at some subgrain boundaries, with a microstructure comparable to that observed in samples aged

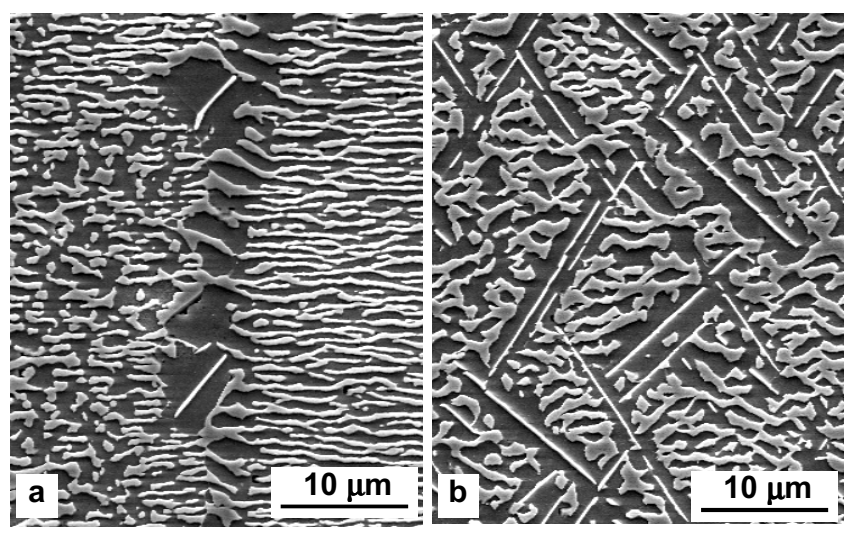

Figure 5. Microstructure of a MC632 specimen after 767 hours of creep at $1050^{\circ} \mathrm{C}$ (longitudinal section): (a) cellular colony at a subgrain boundary and $\gamma-\gamma^{\prime}$ rafted structure in the adjacent subgrains; (b) TCP phase particles in a dendrite core. 

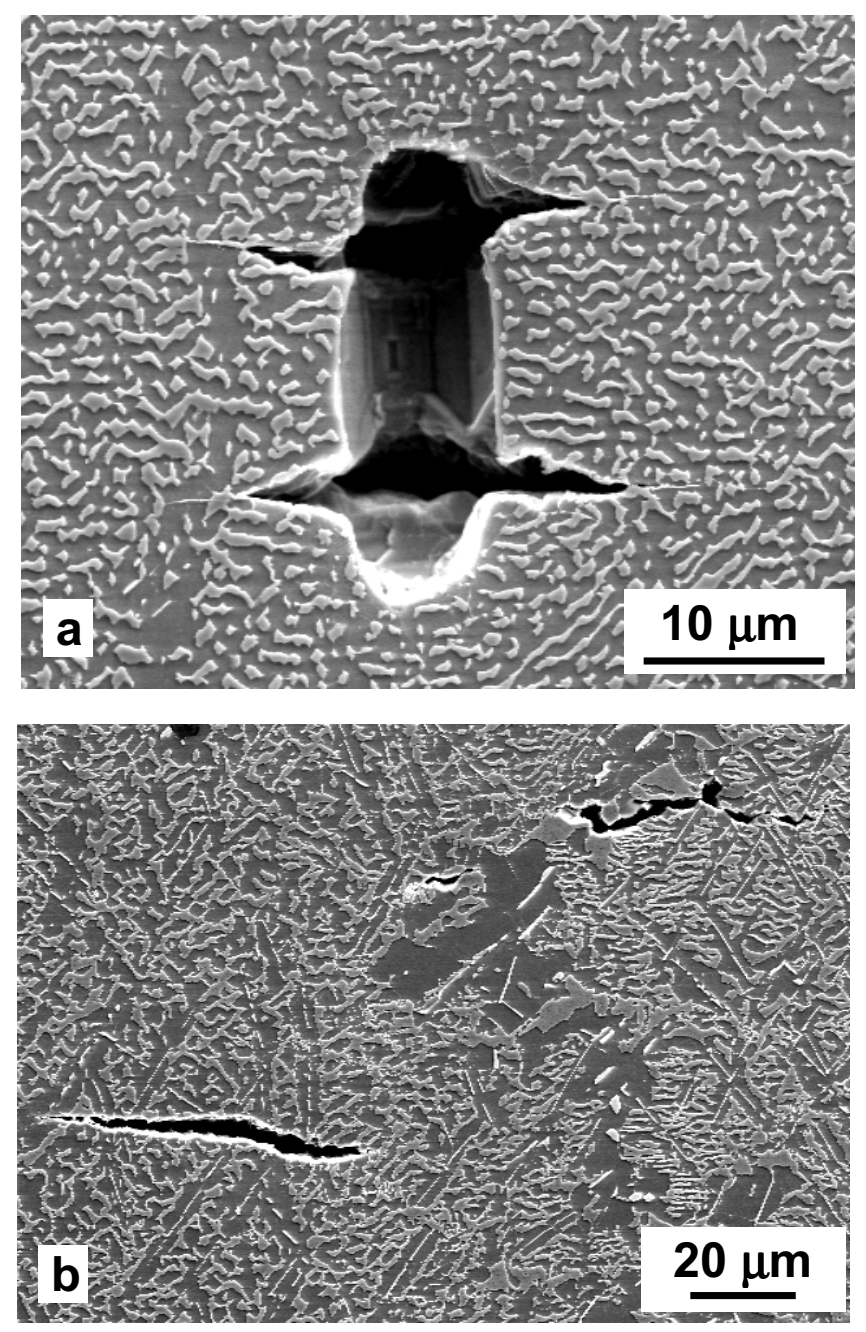

Figure 6. Crack initiation sites observed on longitudinal sections of failed MC632 creep specimens: (a) on a casting porosity, (b) in a dendrite and at a cellular colony boundary.

without external stress. Oriented coalescence of the $\gamma^{\prime}$ precipitates occurred within the subgrains normally to the tensile axis, thus producing the typical regular $\gamma-\gamma^{\prime}$ rafted structure which gives single crystal superalloys their outstanding creep resistance at high temperatures. TCP phase particles precipitated within the cores of the dendrites. The $\gamma-\gamma^{\prime}$ rafted structure is strongly disrupted locally which should have a negative influence on the creep strength of the alloy. It must be pointed out that the microstructural instability encountered within the dendrite cores of MC632 is not cellular colony type, unlike those reported for example in the dendrites of Alloy 5A [9].

As seen on longitudinal section of failed creep specimens, microcracks initiate at different sites. Some cracks initiate on casting porosity as widely reported in single crystal superalloys (Figure 6a). Cracks were also observed to initiate and propagate within the dendrites or at the boundary of some cellular colonies (Figure 6b). In this last case cracks propagate preferentially along the subgrain boundaries which are oriented roughly perpendicularly to the stress axis. The coexistence of different but likely occurring crack initiation sites indicates that cellular colonies are not preferential areas for crack initiation compared to more common microstructural defects.

\section{Secondary Reaction Zones beneath Aluminide Coating}

Microstructure. The microstructure of MC544 as protected by a Pt-modified nickel aluminide coating is shown in Figure 7. The interface region is composed of a $15-20 \mu \mathrm{m}$ thick primary interdiffusion zone (PIZ) and a twice as thick secondary reaction zone (SRZ). The SRZ presents a cellular colony-like microstructure, i.e. a $\gamma^{\prime}$ matrix with elongated $\gamma$ and TCP phase particles.

Such instabilities have been previously reported to appear in highrefractory nickel-based superalloy containing levels of Re in the range 5-6.25 wt.\% beneath an Al-rich protective metallic coating under the primary interdiffusion zone [4,9]. These SRZ were suggested to result from: i) local modifications of composition mainly due to diffusion processes, aluminium especially, from the coating toward the substrate and of nickel and other refractory alloying elements in the opposite direction; ii) the residual stress resulting from the surface preparation of the alloy before coating.

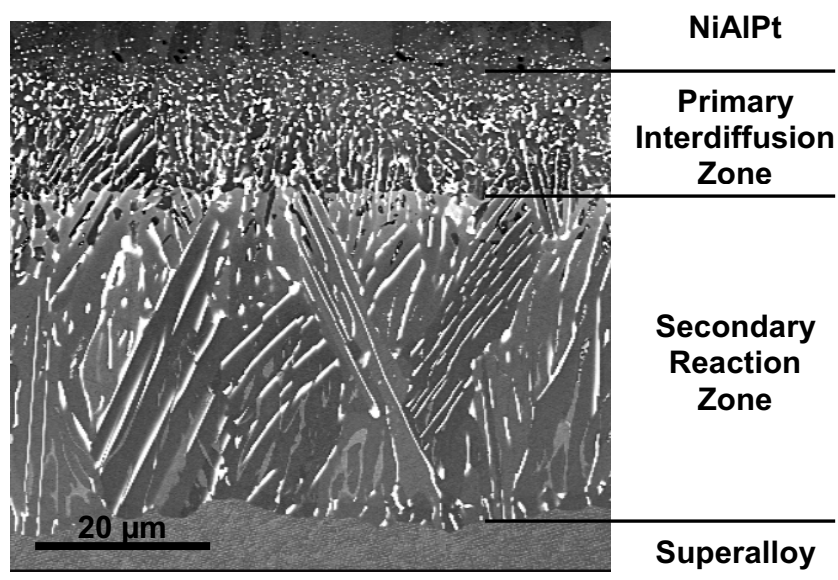

Figure 7: Microstructure of the diffusion zone in as-coated MC544 (SEM, backscattered electron mode).

EBSD analysis (Figure 8) clearly shows that within the SRZ the cellular transformation leading to the characteristic $\gamma^{\prime} / \gamma / \mathrm{TCP}$ phase microstructure occurs together with the recrystallisation of the superalloy affected zone. Elongated recrystallised grains grow normally to the surface with misorientation relative to the original single crystal substrate within the $\left[20^{\circ}, 60^{\circ}\right]$ range (Figures $8 \mathrm{a}$ and $8 b)$. Such high angle misorientations also occur between the grains themselves. No significant crystallographic texture is observed (Figure 8d). The formation of high angle boundaries, on the one hand between the unaffected superalloy and the SRZ, on the other hand between adjacent SRZ grains, is likely to be a weak point in the system with respect to mechanical properties. Moreover, SRZ can extend up to $160 \mu \mathrm{m}$ into the superalloy (MC544 aged at $1100^{\circ} \mathrm{C}$ for 300 hours) thus reducing significantly the alloy load bearing section. 

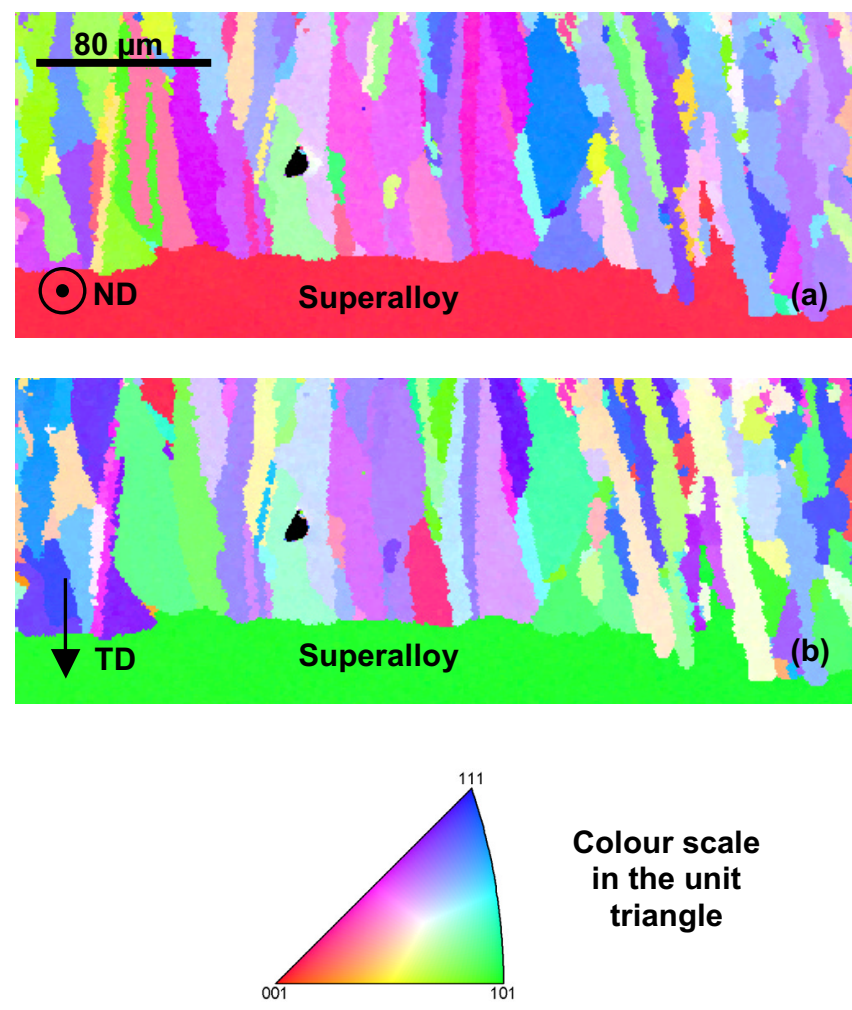

\section{Colour scale in the unit triangle}
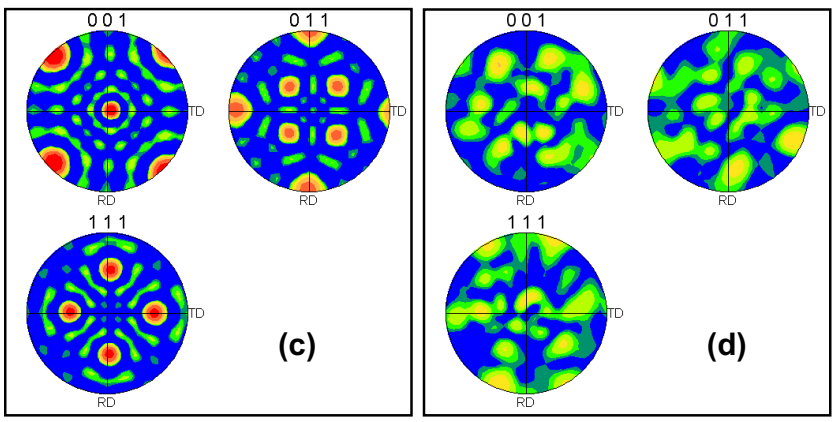

Figure 8. Interface zone between superalloy and SRZ in NiAlPt coated MC544 after exposure for 300 hours at $1100^{\circ} \mathrm{C}$ : EBSD inverse pole figures (a) ND, sample normal, and (b) TD, transverse sample direction; direct pole figures in (c) the superalloy and in (d) the secondary reaction zone.

Creep Behaviour. Creep tests were performed on both bare and coated MC544 specimens at $950^{\circ} \mathrm{C}$ and $300 \mathrm{MPa}, 1050^{\circ} \mathrm{C}$ and $150 \mathrm{MPa}$ and $1150^{\circ} \mathrm{C}$ and $100 \mathrm{MPa}$. The applied load was determined by taking into account the section of the specimen gauge before coating.

In the as-coated system the respective thicknesses of NiAlPt, primary interdiffusion zone and SRZ were $\sim 40 \mu \mathrm{m}, \sim 15 \mu \mathrm{m}$ and $\sim 35 \mu \mathrm{m}$. The thickness of the SRZ has been also measured on transverse sections of failed creep specimens. It increased to about $75 \mu \mathrm{m}$ after 204 hours at $950^{\circ} \mathrm{C}$. The total depth of the diffusion zone has increased from $50 \mu \mathrm{m}$ to $140 \mu \mathrm{m}$ after 199 hours at $1050^{\circ} \mathrm{C}$, and to $110 \mu \mathrm{m}$ after 62 hours at $1150^{\circ} \mathrm{C}$.

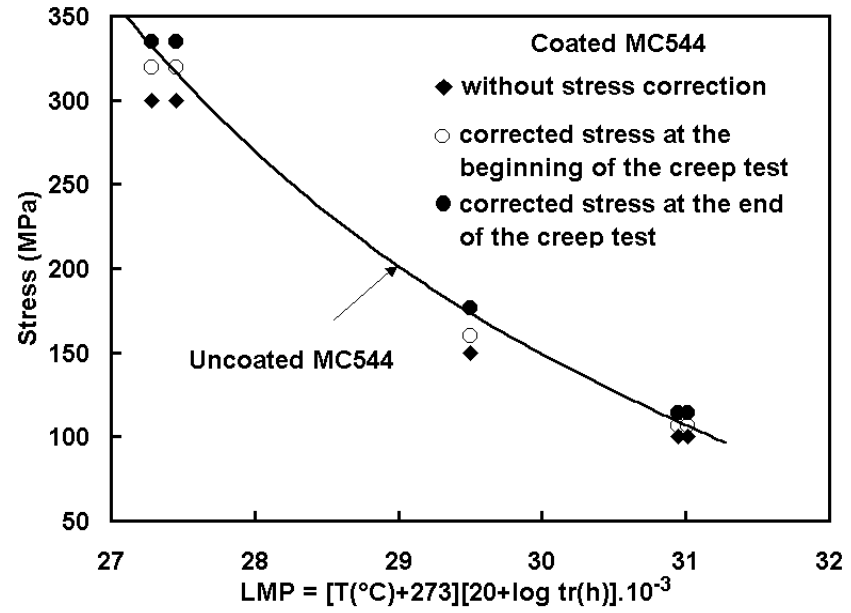

Figure 9. Larson-Miller diagram for stress-rupture life of MC544.

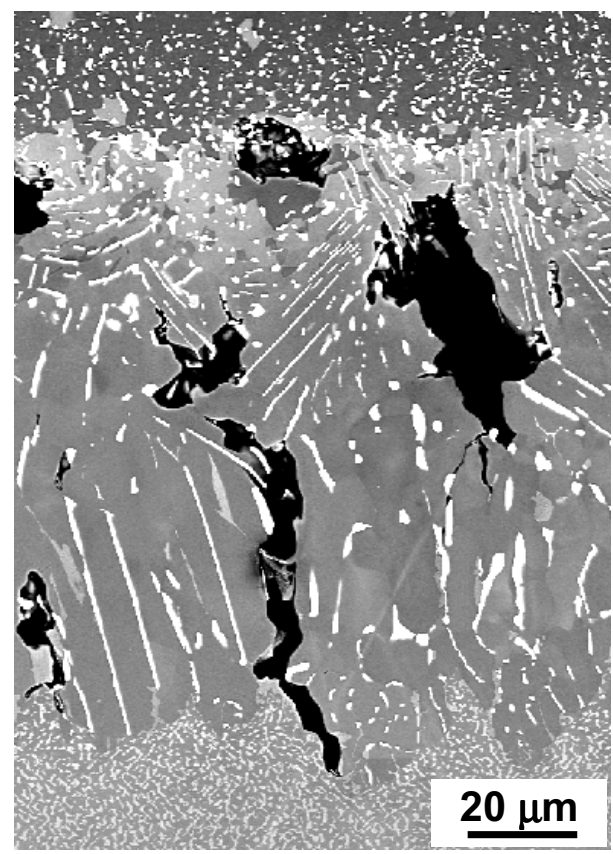

Figure 10. Secondary reaction zone in coated MC544 after 199 hours of creep at $1050^{\circ} \mathrm{C}$ (SEM - backscattered electron mode).

Considering that the creep resistance of both primary and secondary diffusion zones is significantly lower than that of the $\gamma$ $\gamma$ ' microstructure, the true stress acting on the load bearing unaffected alloy was determined at the beginning and at the end of the creep tests by taking into account the total thickness of the interdiffusion zone. The stress-rupture lives of coated MC544 are reported in the Larson-Miller diagram of Figure 9 as a function of the nominal stress (without any correction of section), and also as a function of the stress acting on the unaffected alloy section at the beginning and at the end of the corresponding tests. For the sake of comparison, a Larson-Miller curve for the bare MC544 alloy is reported in this diagram [9]. Without any stress correction, it appears clearly that the presence of the coating significantly reduces the stress-rupture life of MC544. With the corrected values of the stress, the stress-rupture life of the coated material is comparable to that of the bare alloy. 
Microstructural assessments were performed on longitudinal sections of ruptured creep specimens in order to identify the damage modes of the coated material. The SEM micrograph in Figure 10 illustrates the damage experienced in the SRZ after 199 hours of creep at $1050^{\circ} \mathrm{C}$ and $150 \mathrm{MPa}$. It is also representative of the situation observed after creep at $950^{\circ} \mathrm{C}$ and $1150^{\circ} \mathrm{C}$. Microcracks initiate and propagate within the SRZ, along the grain boundaries. The crack may then propagate along the boundary separating the SRZ and the $\gamma-\gamma^{\prime}$ alloy. Excluding the region very close to the fracture surface, i.e. in the necked portion of the specimen, these cracks never propagate into the unaffected superalloy. The SRZ is therefore a poor strength zone which is penalised by its recrystallised structure rather than by its cellular microstructure or by the presence of TCP phase particles. As suggested by the comparative analysis of the creep-rupture times of coated and bare specimens, the thickness of the SRZ is the pertinent parameter required to estimate the deleterious effect of this microstructural instability. Depending on the local section of the single crystal blade, this phenomenon can have a more or less significant effect on the creep behaviour of the component.

Low Cycle Fatigue Behaviour. Figures 11 and 12 compare the LCF behaviours at $650^{\circ} \mathrm{C}$ and $950^{\circ} \mathrm{C}$ respectively of bare and NiAlPt coated MC544 single crystal specimens. Although the tests were conducted in strain-controlled mode, the number of cycles to failure was plotted as a function of stress to take into account the decrease of the load bearing section due to the diffusion zone (PIZ + SRZ). We have also reported in Figures 11 and 12 the stress experienced by the unaffected material by taking a total diffusion zone depth of $50 \mu \mathrm{m}$ corresponding to the ascoated state. As the gauge diameter of the LCF specimen before coating was $4.85 \mathrm{~mm}$, the presence of the coating causes a decrease of $4.1 \%$ of the load bearing section, and thus an equivalent increase of the experienced stress.

In spite of this correction a significant deleterious effect of the presence of the coating on the LCF strength is observed at low stress at $650^{\circ} \mathrm{C}$. On the other hand at $650^{\circ} \mathrm{C}$ for high stresses and at $950^{\circ} \mathrm{C}$ within the whole investigated stress range, there is only a slight decrease in the LCF strength due to the coating. As for the creep behaviour the issue was to determine wether the LCF strength decrease was due to the reduction of the load bearing section, to the coating itself where cracks can initiate, or to the possible role of the SRZ in crack initiation. After corrections have been applied for the load bearing section, the significant deleterious effect still observed at $650^{\circ} \mathrm{C}$ at the lowest stresses must be due to a premature crack initiation on defects different of those typically involved in bare single crystal superalloys such as casting porosity or surface defects. SEM investigations have been performed on fracture surface and longitudinal sections of failed specimens in order to identify the crack initiation sites and to evaluate the possible damage effect of SRZ.

At $650^{\circ} \mathrm{C}$ the rupture initiates systematically at the external surface of the coated specimens (Figure 13a). The cracks then propagate inside the specimen, normal to the stress axis. Observation of secondary cracks on longitudinal section of failed specimens confirm that the cracks initiate from the external surface (Figure 13b) and not on internal defects as in the case of uncoated specimens. Higher magnification observations show that the crack then propagates through the SRZ following the grain

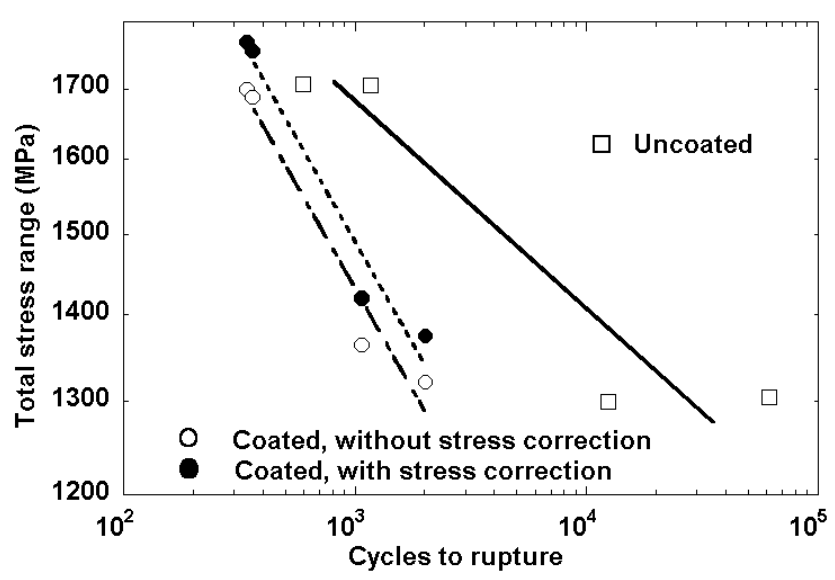

Figure 11. LCF strength at $650^{\circ} \mathrm{C}$ of $\mathrm{MC} 544(\mathrm{R}=-1, \mathrm{f}=0.33 \mathrm{~Hz})$.

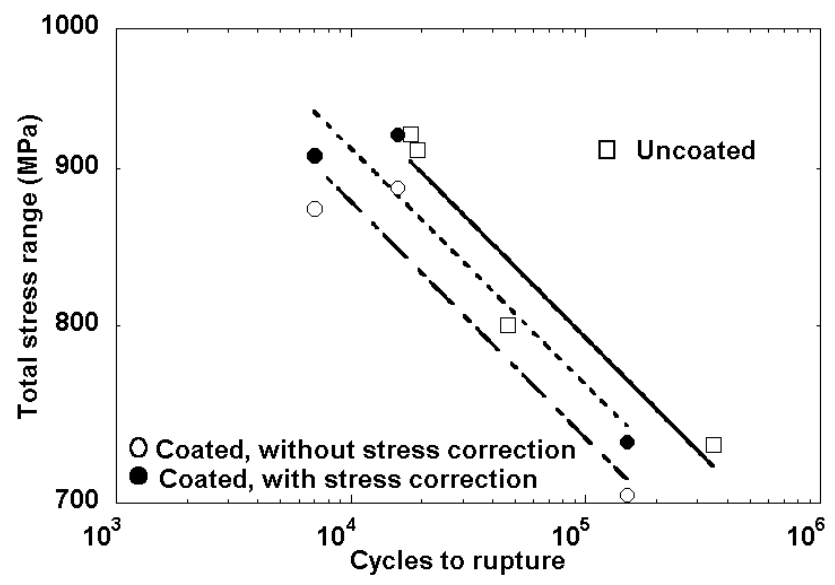

Figure 12 . LCF strength at $950^{\circ} \mathrm{C}$ of $\mathrm{MC} 544(\mathrm{R}=-1, \mathrm{f}=0.33 \mathrm{~Hz})$.

boundaries. The crack can sometimes bifurcate along the grain boundary between SRZ and $\gamma-\gamma^{\prime}$ region, but it always propagates finally through the $\gamma-\gamma^{\prime}$ microstructure normal to the stress axis (Figure 13c). The cracks were never observed to initiate from inside the SRZ nor at the boundary between the SRZ and the unaffected $\gamma-\gamma^{\prime}$ region, but these observations emphasize the weakness of the SRZ grain boundaries. The poor coherence of the $\mathrm{SRZ} / \gamma-\gamma$ ' boundary is demonstrated by the detachment of the external part of the specimen near to the fracture surface as illustrated in Figure 14. However, this phenomenon is more a consequence of the local high strain level than the cause of premature failure of the coated specimen. The deleterious effect of the coating on the LCF strength of MC544 at $650^{\circ} \mathrm{C}$ is thus thought to be due to the inherent lack of ductility of the NiAlPt coating which promotes premature crack initiation in this region, regardless of the effect of the load bearing section reduction.

At $950^{\circ} \mathrm{C}$ rupture always initiates on internal defects in the coated MC544 specimens, regardless of the applied strain (Figure 15a). Periodic cracks are observed normal to the stress axis within the coating layer which exhibits a wavy shape (Figure 15b). These secondary cracks then split along the boundary between the SRZ and the unaffected substrate. These cracks can merge in the region close to the fracture leading locally to complete delamination of the external layer including the coating and the diffusion zone. 

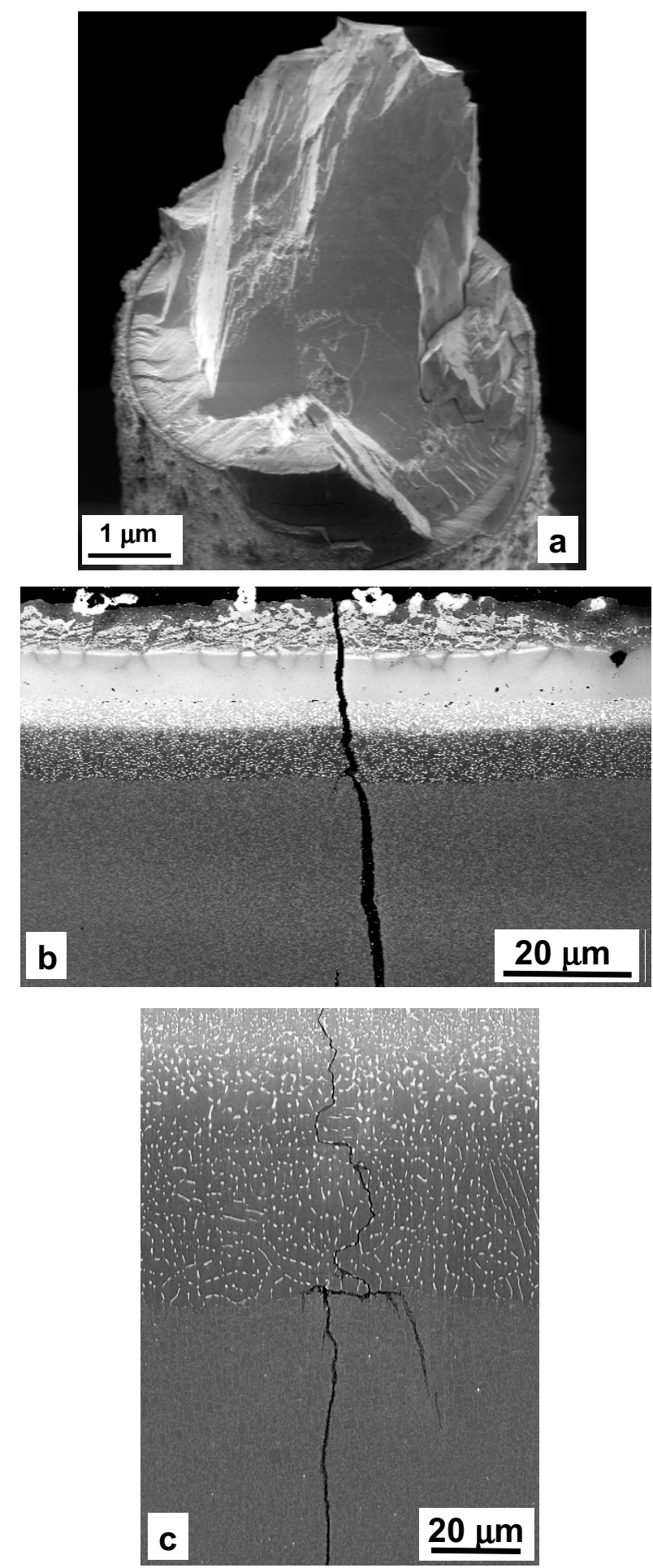

Figure 13. SEM micrographs of a NiAlPt coated MC544 LCF specimen failed at $650^{\circ} \mathrm{C}(1070$ cycles $)$ : (a) rupture initiation at the external surface; (b) secondary crack initiating at the external surface (longitudinal section; SEM in backscattered electron mode); c) propagation of a crack through the SRZ and the $\gamma-\gamma$ ' structure (longitudinal section; SEM in backscattered electron mode).

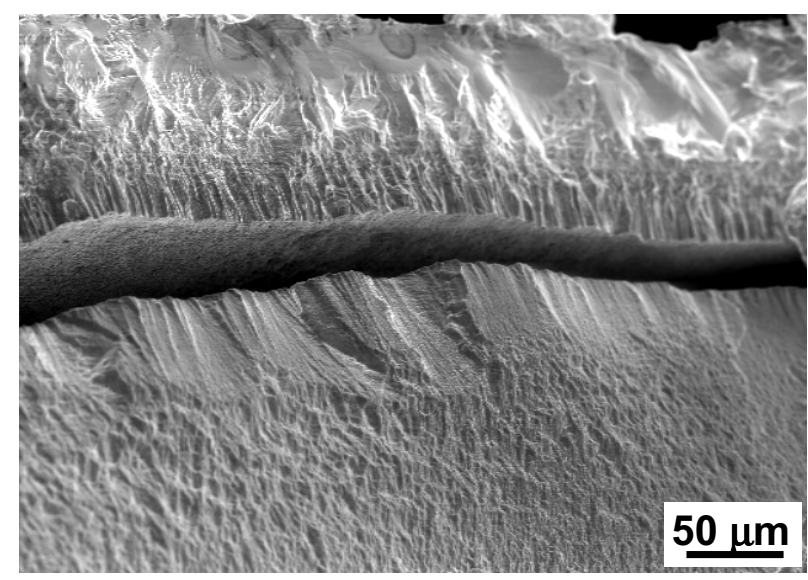

Figure 14. Complete delamination at the boundary between the SRZ and the $\gamma-\gamma$ ' structure close to the fracture surface of a coated LCF MC544 specimen failed at $650^{\circ} \mathrm{C}$.
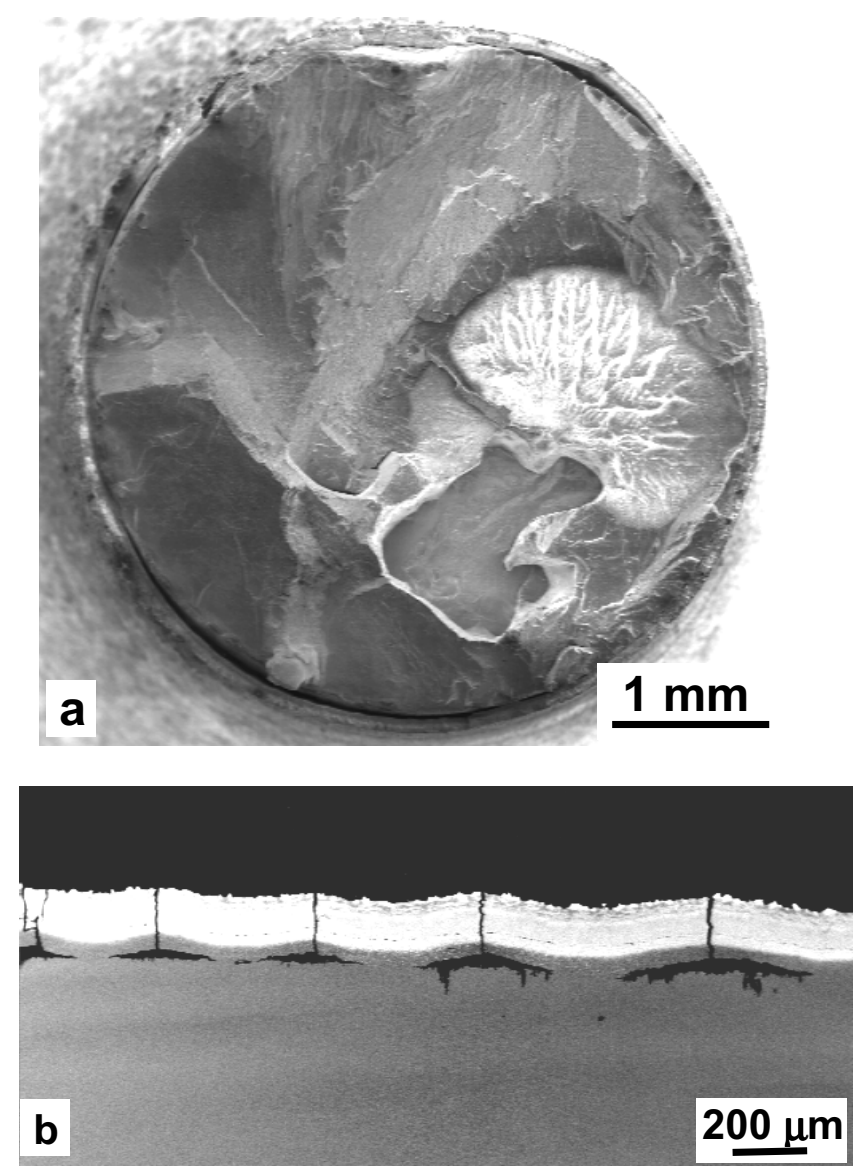

Figure 15. SEM micrographs of a coated MC544 LCF specimen failed at $950^{\circ} \mathrm{C}$ (7010 cycles): (a) internal rupture initiation; (b) secondary cracks within the coating layer (longitudinal section, backscattered electron mode). 
The cracks never propagate inside the unaffected alloy unlike that observed at $650^{\circ} \mathrm{C}$. Only small oxidation pits can be observed in the $\gamma-\gamma^{\prime}$ superalloy originating from the longitudinal cracks which are themselves strongly oxidized.

These observations evidence the poor mechanical strength of the NiAlPt coating which deforms strongly during the LCF tests at $950^{\circ} \mathrm{C}$. Fortunately, this phenomenon has no deleterious influence neither on the crack initiation process leading to the final rupture nor on the LCF strength of the coated material. Thus only the reduction of the load bearing section, resulting from the interdiffusion between the coating and the superalloy substrate, affects the number of cycles to failure.

\section{Discussion}

Cellular colonies observed in MC632 have the same microstructural characteristics as those described in Alloy 5 [9] and SX1 alloy [7, 8]. The occurrence of this cellular transformation at a subgrain boundary was observed to depend on the angular misorientation between the two adjacent subgrains. The minimal value for occurrence of cellular colonies in MC632 is about $10^{\circ}$ as in Alloy 5 and SX1. The fact that no cellular colonies develop in AM1 even at subgrain boundaries with angles as high as $15^{\circ}$ confirms that superalloy composition plays a fundamental role in their formation. Walston et al. suggested that segregation of Re to high angle subgrain boundaries is a strong driving force for nucleation of cellular colonies [9]. EBSD analysis at the scale of a $12 \mathrm{~mm}$ diameter sample brings useful statistical information about the distribution of the subgrain boundaries as a function of their misorientation angle. In the single crystal studied here cellular colonies are present along the whole length of the subgrains with misorientation angles higher than $10^{\circ}$ after ageing at high temperature. A rough estimation of the volume fraction of superalloy transformed by the corresponding cellular transformation gives a maximum value of 1 to $2 \%$. Assuming that the intrinsic strength of cellular colonies with a $\gamma^{\prime}$ matrix is significantly lower than that of the $\gamma-\gamma^{\prime}$ alloy, their presence could lead to an equivalent decrease of the load bearing section and therefore to a slight decrease of the mechanical strength. Microstructural assessment of failed MC632 creep specimens showed that cellular colonies are not more favourable to crack initiation than other internal defects such as casting porosity or unidentified defects within the dendrites. Microcracks are sometimes observed at the interface between a cellular colony and the unaffected $\gamma-\gamma^{\prime}$ alloy, mainly on subgrain boundary segments strongly inclined to the tensile stress axis. As cellular colonies develop only at high angle subgrain boundaries, it is suggested that the weakness of the boundary depends primarily on its misorientation rather than on the presence of the cellular colony. So, from a practical point of view, cellular colonies are not actually a problem because blades containing subgrain boundaries with misorientation angles above $6-8^{\circ}$, and therefore susceptible to contain cellular colonies, are systematically rejected.

The most detrimental microstructural instability in Alloy 5A was reported to be cellular colonies nucleating in dendrite cores due to the local enrichment in Re during the dendritic solidification [9]. Cracks along the interfaces of these cellular colonies were mentioned to cause dramatic reduction of stress-rupture life at $1093^{\circ} \mathrm{C}$. It must be pointed out that such cellular colonies were never observed either in MC632 or in MC544 alloys studied here.
Even if quite numerous needle-like Re-rich particles precipitate within the dendrite core of MC632 during high temperature exposures, they are never associated with cellular transformation of the $\gamma-\gamma^{\prime}$ microstructure. The higher microstructural stability of MC632 and MC544 must be due to their lower content in Re, respectively 3.5 and 4 wt.\%.

Secondary reaction zones appearing in coated MC544 are similar to those previously observed in coated Alloy 5A [9], René N6 [4] and CMSX-10 [5] single crystal superalloys. The contribution of EBSD analysis to the description of this phenomenon has been to prove the polycrystalline character of the cellular transformation zone with quantitative information about the misorientation angles. The formation of these SRZ clearly involves two simultaneous processes: (a) a cellular precipitation process which transforms the initial $\gamma-\gamma^{\prime}$ microstructure in a coarse $\gamma^{\prime}-\gamma$-TCP phase microstructure, first described by Walston et al. [9]; (b) a recrystallisation process leading to a polycrystalline structure. The potential deleterious effects of SRZ on mechanical properties of coated single crystal superalloys were suggested to be [9]: (a) reduction of the load bearing cross section; (b) crack initiation along the boundary between the cell and the unaffected superalloy. Microstructural assessment of the failed coated MC544 creep specimens revealed the intrinsic weakness of the SRZ where microcracks initiate then propagate along their internal grain boundaries. It must be emphasized that the SRZ brittle character is due to its polycrystalline structure and not for instance to the presence of Re-rich TCP phase particles. On the other hand cracks were also seen to propagate along the high angle grain boundary between the SRZ and the superalloy. However, these cracks were never observed to go through the $\gamma-\gamma$, microstructure. Thus, SRZ do not play any role in initiating premature creep failure in coated MC544. Their only deleterious effect was demonstrated to be the decrease of the stress-rupture life due to the reduction of the load bearing high strength $\gamma-\gamma$, microstructure. This aspect can therefore be of concern in the case of thin walls in highly cooled turbine blades where the ratio of superalloy affected by SRZ transformation can become significant.

As far as the LCF behaviour of coated MC544 is concerned, the main issue was to check if SRZ can initiate cracks causing premature failure of the material as compared to the bare one. At $650^{\circ} \mathrm{C}$ the number of cycles to failure is adversely affected by the presence of the aluminide coating, especially at the lowest applied stress level. The reduction of the load bearing cross section due to SRZ formation does not explain this LCF strength decrease. In fact, cracks initiate in the brittle NiAlPt layer and not in the SRZ, then follow the grain boundaries within the SRZ, showing their poor strength, and continue within the superalloy. That explains the resulting loss of LCF strength. At $950^{\circ} \mathrm{C}$, i.e. above its ductileto-brittle transition temperature, the aluminide coating is no longer brittle. The cracks initiate at casting porosity, as typically observed in uncoated specimens. In this case the slight decrease of the LCF strength was shown to be mainly due to the reduction in the load bearing cross section. Under severe laboratory test conditions the NiAlPt layer was strongly deformed and therefore contained numerous cracks propagating within the SRZ. Contrary to what was observed at $650^{\circ} \mathrm{C}$, the cracks did not cross the boundary separating the SRZ and the $\gamma / \gamma^{\prime}$ superalloy, but rather split along this interface. This explains the limited deleterious effect of SRZ on LCF strength at $950^{\circ} \mathrm{C}$ of coated MC544. This 
result agrees with those previously reported on coated MC-NG single crystal alloy [10].

\section{Conclusions}

1. Cellular colonies nucleate during high temperature exposure in MC632 single crystal superalloy at subgrain boundaries with misorientation angles higher than $10^{\circ}$. EBSD analyses clearly shows that a cellular colony grows in epitaxy with the subgrain from which it originates. The grain boundary between the cellular colony and the subgrain into which it grows has therefore the same misorientation as the initial subgrain boundary. The reduction in load bearing cross section of unaffected $\gamma-\gamma^{\prime}$ alloy does not exceed $2 \%$ if the alloy contains subgrain boundaries with misorientation angles in the range $10^{\circ}-15^{\circ}$. During creep at high temperatures microcracks can initiate and propagate along the high angle boundary segments strongly inclined to the tensile stress axis. However, his phenomenon is not more harmful than microcracks originating from casting porosity or from the bulk of the dendrites. In the practical case where single crystal blades containing subgrain boundaries with angles higher than $8^{\circ}$ are rejected, these issues are not of concern.

2. Secondary reaction zones are formed in the MC544 single crystal superalloy beneath the primary diffusion zone of Ptmodified aluminide coating. EBSD analysis demonstrated unambiguously the polycrystalline nature of this cellular transformation area. The only deleterious effect of the SRZ on high temperature stress-rupture creep life is only a reduction of the load bearing cross section of high strength $\gamma-\gamma^{\prime}$ alloy. There is no premature creep failure due to crack initiation in the SRZ. During low cycle fatigue testing of coated MC544 at $650^{\circ} \mathrm{C}$, failure initiates in the brittle NiAlPt coating, and not in the SRZ. This causes a reduction of the LCF strength as compared to the bare material. At $950^{\circ} \mathrm{C}$ the LCF strength of MC544 is only slightly affected by the presence of the coating which has gone through its brittle-to-ductile transition. The main damage mechanism is the reduction of the load bearing cross section due to the diffusion zone between the alloy and the coating.

\section{Acknowledgements}

The authors are grateful to the French Ministry of Defence and to the French Ministry of Transport for partial funding of this work.

\section{References}

1. P. Caron, and T. Khan, "Evolution of Ni-based Superalloys for Single Crystal Gas Turbine Blade Applications," Aerosp. Sci. Technol., 3 (1999), 513-523.

2. D.N. Duhl, "Alloy Phase Stability Requirements in Single Crystal Superalloys," Alloy Phase Stability and Design, ed. G.M. Stocks, D.P. Pope, and A.F. Giamei (Warrendale, PA: MRS, 1991), 389-399.

3. R. Darolia, D.F. Lahrman, and R.D. Field, "Formation of Topologically Close Packed Phases in Nickel-based Single Crystal Superalloys," Superalloys 1988, ed. D.N. Duhl, et al. (Warrendale, PA : TMS, 1988), 255-264.

4. W.S. Walston, K.S. O'Hara, E.W. Ross, T.M. Pollock, and W.H. Murphy, "René N6: Third Generation Single Crystal
Superalloy," Superalloys 1996, ed. R.D. Kissinger, et al. (Warrendale, PA: TMS, 1996), 27-34.

5. G.L. Erickson, "The Development and Applications of CMSX-10," Superalloys 1996, ed. R.D. Kissinger, et al. (Warrendale, PA: TMS, 1996), 35-44.

6. M. Pessah, P. Caron, and T. Khan, "Effect of $\mu$ Phase on the Mechanical Properties of a Nickel-base Single Crystal Superalloy," Superalloys 1992, ed. S.D. Antolovich, et al. (Warrendale, PA: TMS, 1992), 567-576.

7. T.M. Pollock, "The Growth and Elevated Temperature Stability of High Refractory Nickel-Base Single Crystals," Mat. Sc. Eng., B32 (1995), 255-266.

8. J.D. Nystrom, T.M. Pollock, W.H. Murphy, and A. Garg, "Discontinuous Cellular Precipitation in a High-Refractory Nickel-Base Superalloy," Met. Mat. Trans. A, 28 (1997), 19972443.

9. W.S. Walston, J.C. Schaeffer, and W.H. Murphy, "A New Type of Microstructural Instability in Superalloys - SRZ," Superalloys 1996, ed. R.D. Kissinger, et al. (Warrendale, PA: TMS, 1996), 9-18.

10. D. Argence, C. Vernault, Y. Desvallées, and D. Fournier, "MC-NG: a $4^{\text {th }}$ Generation Single-Crystal Superalloy for Future Aeronautical Turbine Blades and Vanes", Superalloys 2000, ed. T.M. Pollock, et al. (Warrendale, PA: TMS, 2000), 829-837.

11. P. Caron, "High $\gamma$ ' Solvus New Generation Nickel-Based Superalloys for Single Crystal Turbine Blade Applications," Superalloys 2000, ed. T.M. Pollock, et al. (Warrendale, PA: TMS, 2000), 737-746. 
